\title{
Comparação das propriedades químicas e do perfil lipídico das farinhas de bocaiuva (Acrocomia spp.) despolpada de forma manual e mecânica
}

\author{
Luane Aparecida do Amaral', Paulo Sérgio Loubet Filho², Leandro Fontoura Cavalheiro', \\ Fábio Galvani ${ }^{3}$, Elisvânia Freitas dos Santos ${ }^{1}$ \\ ${ }^{1}$ Universidade Federal de Mato Grosso do Sul, Campo Grande, Mato Grosso do Sul, Brasil. E-mail: luapamaral@hotmail.com, \\ lernfc@gmail.com, elisvania@gmail.com \\ ${ }^{2}$ Universidade Estadual de Campinas, Campinas, São Paulo, Brasil. E-mail: paullo.loubet@gmail.com \\ ${ }^{3}$ Empresa Brasileira de Pesquisa Agropecuária, Campo Grande, Mato Grosso do Sul, Brasil. E-mail: fabio.galvani@embrapa.br
}

Recebido: 04/06/2018; Aceito: 18/01/2019.

\section{RESUMO}

A palmeira Acrocomia spp, também conhecida como bocaiuva, tem sido explorada de forma extrativista por agricultores de subsistência que vivem na área de ocorrência, gerando fonte de renda e a valorização dos frutos nativos. A bocaiuva é de difícil despolpa, então este estudo tem como objetivo comparar as propriedades químicas e o perfil lipídico das farinhas de bocaiuva despolpadas de forma manual e mecânica. Foram realizadas as análises químicas: umidade, cinzas, lipídios, proteínas, carboidratos e fibras. Os ácidos graxos foram determinados por cromatografia gasosa. Todos os parâmetros químicos diferiram estatisticamente entre as duas farinhas, exceto os valores de proteínas. Os valores de umidade, cinzas e carboidratos foram superiores na farinha da polpa extraída de forma mecânica. Maiores teores de lipídios, fibras e calorias foram encontrados na farinha de despolpa manual. O perfil de ácidos graxos saturados dos óleos da polpa de bocaiuva extraída pelos diferentes métodos foi o mesmo (23\%), dos quais o ácido palmítico foi o componente majoritário. Os ácidos graxos poli- e insaturados reduziram na farinha de extração mecânica. Em conclusão, a farinha de bocaiuva obtida de forma manual apresentou maior valor nutricional, presença de ácidos graxos poli- e insaturados.

Palavras-chave: bocaiuva; extração da polpa; análise de alimentos; ácidos graxos.

\section{Comparison of chemical proprieties and lipids content from bocaiuva's flour (Acrocomia spp.) depulped manually and mechanically}

\begin{abstract}
The palm tree Acrocomia spp, also known as bocauiva, has been explored in an extractive way by subsistence farmers that live around the cultivation area, becoming income and valuing native fruits. However, is difficult to takeoff bocaiuva's pulp, therefore this paper aims to compare chemical proprieties and lipid content from bocaiuva's flour depulped manually and mechanically. Chemical analysis such as moister, ashes, lipids, protein, carbohydrate and fiber were measured. The fatty acids were analyzed by gas chromatography. All parameters showed a statistical difference between both flours, except protein values. The results for moister, ashes and carbohydrates were superior on bocaiuva's flour obtained mechanically, although higher lipid content, fiber, and calories were found in the flour obtained manually from bocaiuva. The saturated fatty acid profile of the pulp oil extracted by different methods was the same (23\%), of which palmitic acid was the major component. The poly and unsaturated fatty acids decrease in mechanical extraction flour. In conclusion, the bocaiuva flour obtained manually, showed higher nutritional value, by the presence of poly and unsaturated fatty acids.
\end{abstract}

Keywords: bocaiuva; pulp extraction; food analysis; fatty acids. 


\section{Introdução}

A bocaiuva pertence à família Palmae (Arecaceae), sendo encontrada no Cerrado, principalmente nos Estados de Mato Grosso do Sul, Minas Gerais, Goiás e Mato Grosso. É popularmente conhecida como bocaiuveira, bacaúva, macaúba, macaíba, coco-babão e imbocaia (Almeida et al., 1998; Áscoli et al., 2015). O fruto de bocaiuva, quando maduro, apresenta polpa oleosa, doce e comestível, de coloração amarela à laranja. Seus frutos são constituídos principalmente por carboidratos, fibras e ácidos graxos insaturados (Hiane et al., 1990; Ramos et al., 2008).

Ainda não se têm evidências de um sistema formal de produção de frutos de bocaiuva na região do Mato Grosso do Sul. O extrativismo em populações silvestres é a única forma de obtenção destes frutos, realizado por agricultores de subsistência que vivem na área de ocorrência natural da espécie. Na região de CorumbáMS, a população tem explorado de forma extrativista a bocaiuva na fabricação de farinha, produto típico que tem sido incorporado a produtos alimentícios, se tornando uma forma de valorizar o fruto regional e gerar renda para muitas famílias (Galvani et al., 2005; Conte, 2008).

A dificuldade encontrada para realização da despolpa manual é a alta aderência da polpa ao endocarpo, surgindo assim a necessidade de desenvolver um protótipo para despolpar a bocaiuva. Em 2008, a Embrapa Pantanal, em parceria com a Organização Não Governamental Ecologia e Ação (ECOA), iniciou um projeto de beneficiamento de bocaiuva, com o intuito de gerar uma alternativa de renda e obter quantidade suficiente de matéria prima para a fabricação de produtos à base de bocaiuva. Dessa forma, foi adquirida uma despolpadora desenvolvida pela Universidade Federal de Viçosa, tendo assim uma alternativa de processamento para extração da polpa da bocaiuva (Galvani e Fernandes, 2010).

Diante disso, este estudo tem por objetivo comparar as propriedades químicas e de ácidos graxos das farinhas de bocaiuva (Acrocomia spp) despolpadas, de forma manual e mecânica.

\section{Material e Métodos}

2.1 Coleta, identificação e processamento da farinha de bocaiuva

Os frutos da bocaiuva (Acrocomia spp) foram coletados no Assentamento Antônio Maria Coelho, Corumbá, Mato Grosso do Sul, nas coordenadas 19¹7'29.07’S, 57³6'0.05'O. Os frutos foram selecionados e pré lavados em água corrente para retirada de sujidades, e sanitizados em solução clorada (200 mg L $\mathrm{m}^{-1}$ ) por 15 minutos. Os frutos foram divididos em dois grupos: 1) Despolpamento manual, utilizando facas de aço inoxidável, 2) Despolpamento mecânico, utilizando um equipamento protótipo (Galvani e Fernandes, 2010). Após a seleção, os frutos para o processo manual foram secos ao sol por um período de 40 minutos para o descascamento e, após serem descascados, passaram por uma secagem ao sol por um período de até 3 horas conforme o nível de insolação antes do despolpamento manual (Dias e Galvani, 2017).

Para os frutos processados mecanicamente, a polpa da bocaiuva foi disposta em bandejas e levada para desidratação em estufa com circulação de ar, à temperatura de $40-50{ }^{\circ} \mathrm{C}$ por um período de 4 horas.

Ambas as polpas desidratadas foram pré trituradas em Cutter $\left(\right.$ SIRE $\left.^{\circledR}\right)$, após, trituradas em moinho (TECNAL $^{\circledR}$ ), e posteriormente peneiradas em tamis malha 20. As farinhas foram armazenadas em freezer convencional a uma temperatura aproximada de $-18^{\circ} \mathrm{C}$ para posteriores análises.

\subsection{Composição química}

Foram realizadas as seguintes análises em triplicata das duas farinhas: umidade: determinada em estufa a $105{ }^{\circ} \mathrm{C}$ até peso constante (AOAC, 2011); cinzas: determinadas em mufla $\left(550^{\circ} \mathrm{C}\right)(\mathrm{AOAC}, 2011)$; lipídios totais: utilizando o método Soxhlet com extração por éter de petróleo; proteínas: avaliado através do teor de nitrogênio total da amostra, pelo método Kjeldahl, determinado ao nível semimicro (AOAC, 2011). Utilizou-se o fator de conversão de nitrogênio para proteína de 6,25; fibra alimentar: o teor de fibra alimentar total foi avaliado pelo método AOAC 985.29; carboidratos: a determinação de carboidratos dos produtos foi realizada por cálculo teórico (por diferença) nos resultados das triplicatas, conforme a fórmula: $\%$ Carboidratos $=100-(\%$ umidade $+\%$ proteína $+\%$ lipídios $+\%$ cinzas $+\%$ fibra alimentar); valor calórico total: o total de calorias (kcal) foi calculado utilizando-se os seguintes valores: lipídios $(9,03 \mathrm{kcal} / \mathrm{g})$, proteína $(4,27 \mathrm{kcal} / \mathrm{g})$ e carboidratos $(3,82$ $\mathrm{kcal} / \mathrm{g}$ ) (Merrill e Watt, 1973).

\subsection{Composição de ácidos graxos}

Para determinar a composição de ácidos graxos, os lipídios das amostras de farinhas foram extraídos pelo método Bligh e Dyer (1959). A esterificação foi realizada de acordo com Maia e Rodriguez-Amaya (1993) e seguida da determinação de ácidos graxos por cromatografia gás-líquido, método recomendado pelo Instituto Adolfo Lutz (2005), empregando cromatógrafo gasoso da marca Shimadzu ${ }^{\circledR}$, modelo GC 2010. Foi utilizada a coluna BPX-70 com a fase estacionária de $70 \%$ cianopropil polisilfenileno-siloxano com $30 \mathrm{~m}$ de comprimento, $0.25 \mathrm{~mm}$ de diâmetro interno e $0.25 \mu \mathrm{m}$ de espessura do filme. Foi utilizado um injetor do tipo split com split de 50:1 na temperatura de $250{ }^{\circ} \mathrm{C}$. As análises 
foram realizadas com o detector do tipo FID na temperatura de $250^{\circ} \mathrm{C}$. A rampa de temperatura da coluna durante as análises foi de inicialmente $80^{\circ} \mathrm{C}$, permanecendo por $3 \mathrm{~min}$. Em seguida, aumentou a uma taxa de $10^{\circ} \mathrm{C} / \mathrm{min}$ até atingir $140^{\circ} \mathrm{C}$ e depois continuou a aumentar a uma taxa de $5^{\circ} \mathrm{C} / \mathrm{min}$ até alcançar $240^{\circ} \mathrm{C}$, onde permaneceu por $5 \mathrm{~min}$.

\subsection{Análise estatística}

Os dados foram analisados pelo software GraphPad Prism $^{\circledR}$, versão 6 e reportados como média \pm desvio padrão. As comparações foram realizadas utilizando o teste $t$ de Student. Os valores foram considerados significantes quando $\mathrm{p}<0,05$.

\section{Resultados e Discussão}

Na Tabela 1 estão representados os valores obtidos na análise da composição química da farinha da polpa por extração manual, em comparação com a farinha da polpa extraída de forma mecânica de frutos de bocaiuva, tendo como referência uma amostra de 100 gramas. Todos os parâmetros químicos diferiram estatisticamente $(\mathrm{p}<0,05)$ entre as duas farinhas, exceto os valores de proteínas. A farinha da polpa extraída manualmente apresentou $11,32 \%$ de umidade e a extração mecânica, 12,46\%. Hiane et al. (1990) (Acrocomia mokayayba Barb. Rodr.) encontraram valor médio de umidade de $13,45 \%$ e Kopper et al. (2009) encontraram, na mesma espécie (Acrocomia aculeata (Jacq.) Lodd. Ex Mart.), 9,85\% em farinhas de polpa de bocaiuva extraída manualmente. Por outro lado, Santos (2017), analisando a farinha da polpa extraída de forma manual na espécie (Acrocomia totai Mart.), encontrou valor de umidade médio de $4,41 \%$. Tal diferença pode ter ocorrido devido ao processo de secagem. Elias et al. (2009) relatam que o teor de umidade está relacionado com os métodos de secagem, binômio tempo/temperatura e período de armazenamento. A bocaiuva destaca-se por seu elevado teor de lipídios (Hiane et al., 1990; Santos, 2017). Esta característica contribui consideravelmente para seu elevado valor energético, podendo contribuir significativamente para elevar o padrão alimentar da população. Em nossos achados, destacam-se os maiores teores de lipídios e fibras encontrados na farinha proveniente de despolpa manual (Tabela 1) quando comparados aos da farinha de despolpa mecânica, o que destaca a importância de estudos como este, que avaliam os diferentes processamentos envolvidos na obtenção de farinhas.

Zanatta (2015) utilizou um sistema mecânico de despolpa e observou que os resultados de lipídios $(14,32 \%)$ na polpa de bocaiuva foram próximos aos encontrados para a despolpa mecânica nesse estudo $(10,11 \%)$. Esse mesmo autor comparou o rendimento de despolpa mecânica e manual e observou que mesmo aplicando altas temperaturas, o despolpamento mecânico não ultrapassou $15 \%$ de rendimento; em contrapartida, a despolpa manual obteve um rendimento de $41,43 \%$, assim, podendo inferir que alguns componentes, como os lipídios, permaneçam aderidos ao endocarpo do fruto. O teor calórico da farinha de despolpa mecânica foi menor que o de despolpa manual, devido a essa redução no teor de lipídios. Além disso, os valores de lipídio e fibra alimentar total em ambas as farinhas foram classificados com alto teor de lipídios e fibras (Brasil, 2012). Considerando que a recomendação de ingestão média diária de fibras para adultos de ambos os sexos com idade entre 19 a 50 anos é de $31,5 \mathrm{~g} / \mathrm{dia}$ (Institute of Medicine, 2002), o consumo de uma porção de $40 \mathrm{~g}$ da farinha de bocaiuva por despolpa manual supre $33,39 \%$ das necessidades diárias de fibra alimentar. Já se considerarmos a composição da farinha de bocaiuva por despolpa mecânica, supre $28,89 \%$ de fibra alimentar. A inserção de fibras na alimentação tem sido associada a efeitos positivos sobre a saúde, pois seu consumo tem sido relacionado à diminuição da incidência de diversos tipos de doenças crônicas não transmissíveis, devido aos seus efeitos benéficos como aumento do volume fecal, estimulação da flora intestinal, aumento da saciedade, normalização de níveis de colesterol e glicemia (Dhingra et al., 2012).

O perfil de ácidos graxos saturados dos óleos extraídos das farinhas da polpa de bocaiuva, extraída tanto manualmente como mecanicamente, foi de $23,26 \%$ e $23,24 \%$, respectivamente; o ácido palmítico foi o componente majoritário dessa classe de lipídios $(17,55$ na farinha despolpada manualmente e $20,51 \%$ na farinha despolpada mecanicamente).

A Tabela 2 mostra a composição de ácidos graxos de farinhas de bocaiuva obtidas por diferentes tipos de despolpamento. Dentre os ácidos graxos insaturados, o teor de ácido graxo oleico (monoinsaturado $\omega-9$ ) foi observado em maior quantia na extração oleosa provinda da fruta despolpada mecanicamente; já o ácido linoleico polinsaturado $\omega-6$ praticamente desapareceu após o mesmo tipo de extração. Observa-se que o processo mecânico de extração da polpa de bocaiuva prejudica a composição de ácidos graxos poliinsaturados e apresenta maior proporção de ácidos graxos saturados do que a fruta despolpada manualmente.

Valores preconizados para uma dieta de $2000 \mathrm{kcal}$ da Dietary Reference Intakes (DRIs) (Institute of Medicine, 2005) sugerem ingestão média de $1,8 \mathrm{~g}$ de ácido alfa-linolênico (ômega 3) e 16g de ácido linoleico (ômega 6), onde 40 gramas de farinha de bocaiuva por despolpa manual suprem $31,55 \%$ e $14,55 \%$ dos respectivos nutrientes, enquanto que a farinha extraída de forma mecânica, $22 \%$ e $1,87 \%$. 
Tabela 1. Caracterização química das farinhas de bocaiuva por despolpa manual e mecânica.

\begin{tabular}{lcc}
\hline & Manual & Mecânica \\
Parâmetros & Média $\pm \mathrm{DP}$ & Média $\pm \mathrm{DP}$ \\
\hline Umidade $(\mathrm{g} / 100 \mathrm{~g})$ & $11,32 \pm 0,27^{\mathrm{b}}$ & $12,46 \pm 0,03^{\mathrm{a}}$ \\
Cinzas $(\mathrm{g} / 100 \mathrm{~g})$ & $2,13 \pm 0,02^{\mathrm{b}}$ & $3,75 \pm 0,00^{\mathrm{a}}$ \\
Proteína $(\mathrm{g} / 100 \mathrm{~g})$ & $4,15 \pm 0,09^{\mathrm{a}}$ & $4,56 \pm 0,17^{\mathrm{a}}$ \\
Lipídios $(\mathrm{g} / 100 \mathrm{~g})$ & $26,27 \pm 0,51^{\mathrm{a}}$ & $10,11 \pm 0,11^{\mathrm{b}}$ \\
Carboidratos $(\mathrm{g} / 100 \mathrm{~g})$ & $29,81 \pm 0,66^{\mathrm{b}}$ & $46,36 \pm 0,12^{\mathrm{a}}$ \\
Calorias $(\mathrm{kcal} / 100 \mathrm{~g})$ & $368,85 \pm 1,70^{\mathrm{a}}$ & $287,86 \pm 0,18^{\mathrm{b}}$ \\
Fibra alimentar total $(\mathrm{g} / 100 \mathrm{~g})$ & $26,31 \pm 0,06^{\mathrm{a}}$ & $22,76 \pm 0,14^{\mathrm{b}}$ \\
\hline
\end{tabular}

DP: Desvio Padrão; Letras diferentes na linha indicam diferença significante pelo teste $t$ de student $(\mathrm{p}<0,05)$.

Tabela 2. Composição de ácidos graxos de farinhas de bocaiuva obtidas por diferentes tipos de despolpamento.

\begin{tabular}{lccc}
\hline Ácidos Graxos & Estrutura & Manual & Mecânica \\
\hline Ácido Caproico & $\mathrm{C} 6: 0$ & 0,16 & 0,03 \\
Ácido Caprílico & $\mathrm{C} 8: 0$ & 0,54 & 0,03 \\
Ácido Cáprico & $\mathrm{C} 10: 0$ & 0,33 & 0,04 \\
Ácido Láurico & $\mathrm{C} 12: 0$ & 2,00 & 0,18 \\
Ácido Mirístico & $\mathrm{C} 14: 0$ & 1,00 & 0,16 \\
Ácido Pentadecílico & $\mathrm{C} 15: 0$ & 0,04 & 0,00 \\
Ácido Palmítico & $\mathrm{C} 16: 0$ & 17,55 & 20,51 \\
Ácido Palmitoleico & $\mathrm{C} 16: 1$ & 0,33 \\
Ácido Margárico & $\mathrm{C} 17: 0$ & 2,69 & 0,05 \\
Ácido Cis-10-Heptadecanóico & $\mathrm{C} 17: 1$ & 0,05 & 0,05 \\
Ácido Esteárico & $\mathrm{C} 18: 0$ & 0,10 & 1,98 \\
Ácido Oleico & $\mathrm{C} 18: 1 \mathrm{n} 9 \mathrm{c}$ & 1,34 & 74,05 \\
Ácido Linoleico & $\mathrm{C} 18: 2 \mathrm{n} 6 \mathrm{c}$ & 65,99 & 0,75 \\
Ácido Linolênico & $\mathrm{C} 18: 3 \mathrm{n} 3$ & 5,82 & 0,99 \\
Ácido Araquídico & $\mathrm{C} 20: 0$ & 1,42 & 0,18 \\
Ácido Cis-11- Eicosenoico & $\mathrm{C} 20: 1$ & 0,19 & 0,26 \\
Ácido 11-14- Eicosadienoico & $\mathrm{C} 20: 2$ & 0,23 & 0,03 \\
Ácido Araquidônico & $\mathrm{C} 20: 4 \mathrm{n} 6$ & 0,06 & 0,02 \\
Ácido Behênico & $\mathrm{C} 22: 0$ & 0,00 & 0,03 \\
Ácido Tricosanoico & $\mathrm{C} 23: 0$ & 0,02 & 0,02 \\
Ácido Lignocérico & $\mathrm{C} 24: 0$ & 0,02 & 0,02 \\
Saturado & & 0,03 & 23,24 \\
Monoinsaturado & & 23,26 & 74,68 \\
Polinsaturado & & 69,00 & 1,79 \\
Não identificado & & 7,30 & 0,29 \\
\hline
\end{tabular}

Apesar de tal método otimizar a produção, visto que o equipamento tem capacidade de despolpar cerca de 20 $\mathrm{kg}$ de frutos em aproximadamente 8 minutos (Galvani e Fernandes, 2010), o despolpamento mecânico não mantém todas as características nutricionais funcionais dos óleos essenciais e das fibras alimentares que compõem a bocaiuva.

Os ácidos graxos poli- e insaturados são nutrientes essenciais que são denominados gorduras saudáveis, atuando na proteção contra doenças cardiovasculares, mostrando-se adequadas para o consumo in natura (Santos et al., 2013) e emprego no desenvolvimento de produtos como sorvetes, cupcakes e doces (Boff, 2011; Vieira et al., 2017), substituindo tecnologicamente altos teores de gorduras saturadas por poli- e insaturadas ou fibras dietéticas.

\section{Conclusões}

Em conclusão, a farinha de bocaiuva obtida de forma manual apresentou maiores teores de lipídios, fibras e ácidos graxos poli- e insaturados. Assim, faz-se necessário mais estudos que possam otimizar o processo mecânico a fim de diminuir perdas nutricionais. Por fim, nossos achados ressaltam a importância de conhecer os diferentes métodos de processamento dos alimentos e suas vantagens e desvantagens.

\section{Referências Bibliográficas}

Almeida, S.P., Proença, C.E.B., Sano, S.M., Ribeiro, J.F., 2017. Cerrado: espécies vegetais úteis. Planaltina - DF, Embrapa-CPAC, p. 14-19. 
AOAC International, 2011. Official Methods of Analysis of AOAC International, décima oitava ed. Gaithersburg, Washington.

Áscoli, A.A., Pereira, A.C., Costa, E., Jorge, M.H.A., Maruyama, W.I., 2015. Ambientes protegidos e substratos para mudas de bocaiuva oriundas do campo. Revista de Agricultura Neotropical, 2, 23-28.

Bligh, E.G., Dyer, W.J., 1959. A rapid method of total lipid extraction and purification. Canadian Journal of Biochemistry and Physiology, 37, 911-917.

Boff, C.G.E., 2011. Desenvolvimento de sorvete de chocolate utilizando fibra de casca de laranja como substituto de gordura. Trabalho de conclusão de curso, Instituto de Ciência e Tecnologia de Alimentos, Universidade Federal do Rio Grande do Sul, Porto Alegre.

Brasil, 2012. Resolução n. 54, de 12 de novembro de 2012. http://portal.anvisa.gov.br/documents/\%2033880/2568070/rdc 0054_12_11_2012.pdf/c5ac23fd-974e-4f2c-9fbc48f7e0a31864 (Acessado 25 de março de 2019).

Conte, M., 2008. Farinha de bocaiuva corumbaense ganha mercado brasileiro. Corumbá - MS, Diário Corumbaense, p. 340.

Dhingra, D., Michael, M., Rajput, H., Patil, R.T., 2012. Dietary fibre in foods: a review. Journal of Food Science and Technology, 49(3), 255-266.

Dias, F.R.T., Galvani, F., 2017. Custeio e investimento do sistema artesanal de produção da farinha de bocaiuva. Corumbá - MS, Embrapa Pantanal.

Elias, M.C., Lopes, V., Gutkoski, L.C., Oliveira, M., Mazzutti S., Dias, A.R.G., 2009. Umidade de colheita, métodos de secagem e tempo de armazenamento na qualidade tecnológica de grãos de trigo. Ciência Rural, 39, 1-4.

Galvani, F., Fernandes, J., 2010. Extração mecânica da polpa da bocaiuva coletada na região de Miranda, MS. Circular técnica, Embrapa, p. 1-5.

Galvani, F., Lisita, F.O., Lara, J.A.F., Jorge, M.H.A., Clemente, P.R., Inamasu, R.Y., Salis, S.M., 2005. Potencial da bocaiuva (Acrocomia aculeata) como fonte de óleo para a produção de biodiesel, in: Congresso brasileiro de plantas oleaginosas, óleos, gorduras e biodiesel. Lavras, Universidade Federal de Lavras, p. 277-281.

Hiane, P.A., Penteado, M.V.C., Badolato, E., 1990. Teores de ácidos graxos e composição centesimal do fruto e da farinha da bocaiuva (Acrococomia mokayáyba Barb. Rodr.). Alimentos e Nutrição, 2, 21-26.
Institute of Medicine, 2002. Dietary reference intakes (DRIs): Recommended intakes for individuals, macronutrientes. Washington (DC): Food and Nutrition Board, Institute of Medicine, National Academy Press.

Institute of Medicine, 2005. Dietary Reference Intakes (DRIs) for: energy, carbohydrate, fiber, fat, fatty acids, cholesterol, protein and amino acids (macronutrients). Washington (DC): Food and Nutrition Board, Institute of Medicine, National Academy Press.

Instituto Adolfo Lutz, 2005. Métodos físico-químicos para análise de alimentos, quarta ed. Brasília, Ministério da Saúde.

Kopper, A.C., Saravia, A.P.K., Ribani, R.H., Lorenzi, G.M.A.C., 2009. Utilização tecnológica da farinha de bocaiuva na elaboração de biscoitos tipo cookie. Alimentos e Nutrição Araraquara, 20, 463-469.

Maia, E.L., Rodriguez-Amaya, D., 1993. Avaliação de um método simples e econômico para a metilação de ácidos graxos com lipídios de diversas espécies de peixes. Revista Instituto Adolfo Lutz, 53, 27-35

Merrill, A.L., Watt, B.K., 1973. Energy values of foods: basis and derivation. Washington, USDA, p. 74.

Ramos, M.I.L., Ramos Filho, M.M., Hiane, P.A., Braga Neto, J.A., Siqueira, E.M.A., 2008. Qualidade nutricional da polpa de bocaiúva Acrocomia aculeata (Jacq.) Lodd. Ciência e Tecnologia de Alimentos, 28, 90-94.

Santos, M.F.G., Alves, R.E., Ruíz-Méndez, M.V., 2013. Minor componentes in oils obtained from Amazonian palm fruits. Grasas y aceites, 64, 531-536.

Santos, M.M.R., 2017. Avaliação do consumo de diferentes concentrações de farinha de bocaiuva em ratos wistar alimentados com dieta hipercalórica. Dissertação (Programa de Pós-Graduação em Saúde e Desenvolvimento na Região Centro Oeste), Faculdade de Medicina, Universidade Federal de Mato Grosso do Sul, Campo Grande - MS.

Vieira, P.A.Z., Scheidt, R.F., Santos, M.M.R., Candido, C.J., Dos Santos, E.F., Novello, D., 2017. Cupcakes adicionados de farinha de bocaiúva: caracterização físico-química e avaliação sensorial entre crianças. Revista da Universidade Vale do Rio Verde, 15(2), 501-513.

Zanatta, S., 2015. Caracterização da macaúba (casca, polpa e amêndoa) e análise sensorial através da educação do gosto. Dissertação (Centro de Energia Nuclear na Agricultura), Universidade de São Paulo, Piracicaba - SP. 